\title{
EL REGIONALISMO SUDAMERICANO Y EL GIRO HACIA LA DESINTEGRACIÓN: ALGUNAS REFLEXIONES
}

\author{
SOUTH-AMERICAN REGIONALISM AND THE TURN \\ TOWARDS DISINTEGRATION: SOME REFLECTIONS
}

\section{LE RÉGIONALISME SUD-AMÉRICAIN ET LE VIRAGE VERS LA DÉSINTEGRATION : QUELQUES RÉFLEXIONS}

\author{
Bárbara Carvalho Neves \\ Universidade Estadual Paulista \\ barbara.neves@unesp.br \\ Karina Lilia Pasquariello Mariano \\ Universidade Estadual Paulista \\ karina.mariano@unesp.br
}

\begin{abstract}
RESUMEN: El inicio de la segunda década del siglo Xxi representó retrocesos en los impulsos regionalistas latinoamericanos y estuvo marcado por el desmantelamiento de Unasur, la parálisis de ALBa y problemas en la Celac y en el Mercosur. Gran parte de los estudios sobre el tema apuntan las tensiones en estos mecanismos regionales como resultado de múltiples factores coyunturales, como la muerte del presidente venezolano Hugo Chávez, el aumento gradual de la grieta política en Brasil y Argentina, especialmente a partir del impeachment brasileño y el "giro a la derecha" en la región, así como la ampliación de la presencia de actores extrarregionales como China y Estados Unidos. A partir de un análisis procesual e institucional, este artículo discute cómo las instituciones regionales sudamericanas reaccionaron a los periodos de crisis actuales. Se argumenta que el desmantelamiento de Unasur no es simplemente resultado de los cambios sistémicos del periodo, sino que es un reflejo de la trayectoria institucional latinoamericana y de sus antecedentes críticos. A su vez, se concluye que el contexto histórico puede ser la oportunidad que estimula la desintegración latinoamericana, pero no su causa.
\end{abstract}

Palabras clave: integración económica; organización intergubernamental;

América del Sur; regionalismo. 
Abstract: The beginning of the second decade of the $21^{\text {st }}$ century brought with it setbacks to the drive for Latin American regional unity, marked by the dismantling of Unasur, the paralysis of ALBA and problems with Celac and Mercosur. Many studies on the topic point to greater tensions in these regional mechanisms as a result of various circumstantial factors such as the death of the Venezuelan President Hugo Chávez, the increasing polarization of politics in Brazil and Argentina (especially since the impeachment of Dilma Rousseff), the "Right Turn" taken by the region, and the expanding presence of extraregional actors such as China and the United States. With a process-based and institutional analysis, this article discusses how South American regional institutions reacted to the current periods of crisis. It argues that the dismantling of Unasur is not simply a result of the systemic changes undergone in this period, but a reflection of the Latin American institutional direction of travel and its critical antecedents. It concludes that the historical context might be the opportunity that gave rise to this process of disintegration, but not its cause.

Keywords: economic integration; intergovernmental organization;

South America; regionalism.

\section{Traducción de Fionn Petch, cm Idiomas}

Résumé : Le début de la deuxième décennie du xxie siècle a représenté des reculs dans les élans régionalistes latino-américains et a été marqué par le démantèlement de l'Unasur, la paralysie de l'ALba et des problèmes à Celac et Mercosur. Une grande partie des études sur le sujet soulignent les tensions dans ces mécanismes régionaux en raison de multiples facteurs conjoncturels, tels que la mort du président vénézuélien Hugo Chávez, l'augmentation progressive du clivage politique au Brésil et en Argentine, notamment à partir de l'impeachment brésilien et du « virage à droite » dans la région, ainsi que de l'expansion de la présence d'acteurs extra-régionaux comme la Chine et les États-Unis. À partir d'une analyse procédurale et institutionnelle, cet article discute de la manière dont les institutions régionales sud-américaines ont réagi aux périodes de crise actuelles. Il est avancé que le démantèlement de l'Unasur n'est pas simplement le résultat des changements systémiques de la période, mais est le reflet de la trajectoire institutionnelle latino-américaine et de ses antécédents critiques. Aussi, il est conclu que le contexte historique peut êtrel'opportunité qui stimule la désintégration latino-américaine, mais pas sa cause. 
Mots-clés : intégration économique ; organisation intergouvernementale ;

Amérique du Sud; régionalisme

Traducción de Rafael Segovia, cm Idiomas

Fecha de recepción: marzo de 2021.

Fecha de aceptación: octubre de 2021.

\section{INTRODUCCIÓN}

T a primera década de 2000 simbolizó en Latinoamérica un impulso integracionista bajo el fenómeno del regioUnalismo posliberal ${ }^{123}$ que, en conjunto con el movimiento del "giro a la izquierda", ${ }^{4}$ se convirtió en un momento en el cual el regionalismo fue entendido como una alternativa propositiva para el fortalecimiento de los países latinoamericanos y para su mejor inserción en el sistema internacional. Hasta 2010, este impulso regional simbolizó la creación y mo-

${ }^{1}$ El regionalismo posliberal es un movimiento que se desarrolló en los países latinoamericanos, caracterizado por la reinserción de la política en las iniciativas regionales, incluyendo en su agenda la necesidad de suprimir las asimetrías entre los países, así como incluir la participación social, retomando el Estado su posición del actor más importante para la dinámica regional. José Antonio Sanahuja, "Del 'regionalismo abierto' al 'regionalismo post-liberal'. Crisis y cambio en la integración regional en América Latina”, Anuario de la Integración Regional de América Latina y el Gran Caribe 2008-2009 (2009), pp. 11-54; Pedro da Motta Veiga y Sandra Ríos, "O Regionalismo Pós-Liberal na América do Sul: origens, iniciativas e dilemas", Cepal, Serie Comercio Internacional, 82 (2007).

${ }^{2}$ Sanahuja, art. cit.

${ }^{3}$ Veiga y Ríos, art. cit.

${ }^{4}$ El "giro a la izquierda" configura el periodo de cambio político en Latinoamérica, cuyos procesos electorales resultaron en gobiernos de izquierda y centro-izquierda. Véase José Luis Fiori, "A virada à esquerda na América do Sul", Valor Econômico, 9 de enero de 2006, http://www.cnmcut.org.br/conteudo/a-virada-a-esquerda-na-americado-sul (consulta del 13 de octubre de 2017). 
dificación ${ }^{5}$ de varios espacios de diálogo y mecanismos regionales, entre ellos: la Reunión de los Jefes y Jefas de Estado de Sudamérica y la Iniciativa para la Integración de la Infraestructura Regional Sudamericana (IIRSA) en 2000; la Comunidad de Naciones Suramericanas (Casa) y la Alianza Bolivariana para los Pueblos de Nuestra América (ALBA) en 2004; la Unión de Naciones Suramericanas (Unasur), en 2008, y la Comunidad de Estados Latinoamericanos y Caribeños (Celac) en 2010.

Aunque hubo avances y éxitos en la respuesta a las demandas regionales comunes a partir de estas instituciones y foros, el inicio de la segunda década del siglo xxi representó retrocesos en los impulsos regionalistas apuntados, delimitando el nuevo contexto socioeconómico y político latinoamericano que encontraría su ápice en 2019, con el desmantelamiento de Unasur, ${ }^{6}$ la tensión del Mercado Común del Sur (Mercosur) y la parálisis de ALBA, Celac y de la Reunión de Jefes y Jefas de Estados Suramericanos, cuyo último encuentro fue en 2014. Este escenario de desconstrucción de las instituciones regionales en Latinoamérica es resultado de múltiples factores que reflejan, después de más de 10 años, la construcción de instituciones regionales vulnerables a los cambios políticos y económicos en la región debido a limitaciones estructurales para reaccionar adecuadamente al aumento de demandas en periodos de tensión o crisis de sus países miembros. ${ }^{7}$

El tensionamiento de los mecanismos regionales latinoamericanos se inició a partir de 2013, con la muerte del presi-

${ }^{5}$ El Mercado Común del Sur (Mercosur), creado bajo el ímpetu del regionalismo abierto, pasó por diferentes actualizaciones y redireccionamientos en sus actividades y planes de acción, incorporando la cuestión social y de participación democrática, resultado del movimiento posliberal.

${ }^{6}$ Nicolás M. Comini y Alejandro Frenkel, "Unasur on the edge", en D. Nolte y B. Weiffen (org.), Regionalism under stress: Europe and Latin America in comparative perspective, Londres, Routledge, 2020.

${ }^{7}$ Detlef Nolte y Brigitte Weiffen, "Introduction - Regionalism under stress", en ibid., pp. 15-33. 
dente venezolano Hugo Chávez y el aumento gradual de la crisis política brasileña ya al final del primer gobierno de Dilma Rousseff, situación agravada a partir de 2014, con el avance de la Operación Lava Jato $^{8}$ en Brasil. $^{9}$ A su vez, la disminución de la previsibilidad política brasileña, así como el "giro a la derecha" a partir de $2015,{ }^{10}$ con la elección de gobiernos de derecha y extrema derecha en el continente, ${ }^{11}$ alejaron los países de esos proyectos regionales posliberales, hasta entonces considerados alternativas necesarias al desarrollo latinoamericano. ${ }^{12}$

Se entiende que el escenario creado desde 2013, pero con énfasis a partir de 2017 frente a la no elección de un Secretario General en Unasur, presenta condiciones permisivas que, así como ha sido discutido por el institucionalismo histórico (IH) -en el ámbito de los estudios de coyunturas críticas-, disminuyen las contingencias existentes para la agencia de los actores, posibilitando cambios que impactan el futuro de la institucionalidad establecida. ${ }^{13}$ La caracterización del periodo como una coyuntura crítica que culmina en

${ }^{8}$ La Lava Jato es una investigación de la Policía Federal (PF) brasileña que desveló grandes esquemas de corrupción, desvío y blanqueo de dinero entre empresas brasileñas, funcionarios públicos y políticos brasileños y de otros países de América Latina, como el expresidente Pedro Pablo Kuczynski, en Perú, y Rafael Correa, en Ecuador.

${ }^{9}$ Comini y Frenkel, art. cit.

${ }^{10}$ Luis Alexandre Fuccille, Marcelo P. Mariano, Harold Ramanzini Júnior y Rafael R. de A. Almeida, "O governo Dilma Rousseff e a América do Sul: A atuação brasileira na Unasul (2011-2014)", Colombia Internacional, núm. 92 (2017), pp. 43-72, https://doi.org/10.7440/colombiaint92. 2017.02

${ }^{11}$ A. R. Hoffmann, "Mercosur between resilience and disintegration", en Nolte y Weiffen, op. cit., 119-132. Routledge.

12 José Antonio Sanahuja y Camilo López Burian, "Latin American neo-patriot far-right: between the crisis of globalisation and regional political processes", en Gisela Pereyra Doval y Gastón Souroujon (eds.), Global Resurgence of the Right, Londres, Routledge, 2021.

${ }^{13}$ Giovanni Capoccia, "Critical Junctures", en K. O. Fioretos, T. G. Falleti y A. D. Sheingate (org.), The Oxford handbook of historical institutionalism, Reino Unido, Oxford University Press, 2016. 
el desmantelamiento de Unasur y en la parálisis o tensión de las demás instituciones regionales sudamericanas ${ }^{14}$ dialoga con la discusión desarrollada por Capoccia y Kelemen. ${ }^{15}$ De acuerdo con estos autores, las "coyunturas críticas son momentos en los cuales la inseguridad acerca del futuro de una institución permite que los agentes políticos y sus decisiones tengan un rol decisivo en redireccionarla a una nueva trayectoria que pueda perdurar por un largo periodo de tiempo". ${ }^{16}$

En ese sentido, la inseguridad frente a la inestabilidad se configura como uno de los elementos críticos para la manutención, avance o desmantelamiento de las instituciones creadas en la década de 2000. ${ }^{17}$ Este problema se ve impulsado principalmente por la polarización ideológica y política en el ámbito regional. ${ }^{18} \mathrm{Al}$ mismo tiempo, se reconoce que esa tendencia afecta de forma distinta las experiencias de integración, aunque congregue a los mismos actores, como consecuencia de las diferentes trayectorias institucionales de cada mecanismo regional. ${ }^{19}$

A partir de estas reflexiones, se cuestiona: ¿cómo reaccionan esas instituciones a la crisis regional, en especial en un escenario de estímulo a la desintegración? En general, se ha

14 Guadalupe G. González, Mónica Hirst, Carlos Luján, Carlos A. Romero y Juan Gabriel Tokatlian, "Coyuntura crítica, transición de poder y vaciamiento latinoamericano”, Nueva Sociedad (2021), núm. 291, https:/ / nuso.org/articulo/coyuntura-critica-transicion-de-poder-y-vaciamientolatinoamericano/

15 G. Capoccia y R. D. Kelemen, "The Study of Critical Junctures: Theory, Narrative, and Counterfactuals in Historical Institutionalism", World Politics, 59, núm. 3 (2007), pp. 341-369. https://doi.org/10.1017/ S0043887100020852

16 Capoccia, Giovanni. art. cit. pp. 148.

${ }^{17}$ Elsa Llenderrozas, "Unasur: desafíos geopolíticos, económicos y de política exterior”, Pensamiento Propio 42, s/v (2016), pp. 195-214.

18 Víctor Manuel Mijares y Sara Ramírez Hernández, "El factor Venezuela en la crisis del regionalismo posthegemónico", documento de trabajo, 2020.

${ }^{19}$ Brigitte Weiffen, "Stress factors and their impact on regionalism", en Nolte y Weiffen, op. cit., pp. 15-33. 
vinculado la tendencia desintegracionista de América del Sur en los últimos años a esa polarización política e ideológica de los gobiernos, principalmente como resultado del posicionamiento antiintegracionista de importantes sectores de la burguesía empresarial brasileña. ${ }^{20}$

Sin embargo, podemos identificar que la postura de un mismo país no es igual en todos los procesos. De esa manera, nuestro objetivo es evaluar cómo las instituciones regionales reaccionan a coyunturas de inseguridad acerca del futuro, especialmente considerando las experiencias de Unasur. A partir de un análisis institucional procesual, este artículo argumenta que las instituciones regionales reaccionan al contexto de crisis considerando las posibilidades constituidas a lo largo de su existencia. Por lo tanto, la respuesta por desintegración, parálisis o por el mantenimiento del mecanismo, aunque tensionado, no resulta específicamente de los cambios políticos, sino de la propia trayectoria institucional de esos procesos integracionistas, marcados por limitaciones estructurales ${ }^{21}$ que demarcan ciclos sucesivos de apoyo y desgaste al regionalismo. ${ }^{22}$

Para desarrollar el argumento, dividimos este artículo en tres secciones. En la primera presentamos un análisis histórico procesual de los ciclos del regionalismo sudamericano a partir de la contribución teórica del institucionalismo histórico. En la sección siguiente mostramos la validez de la argumentación mediante la discusión sobre cómo esas características explican la disolución de Unasur. En esta segunda sección se destaca la importancia de comprender la trayectoria del proceso regional para entender el momento presente, cuya clave analítica corresponde a las iniciativas en infraestructura regional que se sostienen a pesar de y en

${ }^{20}$ Javier. A. Vadell y Clarisa Giaccaglia, "El rol de Brasil en el regionalismo latinoamericano: la apuesta por una inserción internacional solitaria y unilateral", Foro internacional, 60, 3, (2020), pp. 1041-1080.

${ }^{21}$ José Briceño Ruiz y Andrés Rivarola (org.), Regionalism in Latin America: Agents, systems and resilience, Londres, Routledge, 2021.

${ }^{22}$ Comini y Frenkel, art. cit. 
medio de la crisis de Unasur. Por último, la parte final del artículo elabora sobre las conclusiones y perspectivas iniciales del análisis procesual e institucional del regionalismo sudamericano, que puede servirnos para comprender las demás trayectorias y respuestas de los proyectos de integración en América del Sur frente a un contexto de crisis o tensión.

TRAYECTORIA Y CARACTERÍSTICAS DE LOS CICLOS DEL REGIONALISMO SUDAMERICANO

A partir de los estudios del institucionalismo histórico de Fioretos, Faletti y Sheingate, ${ }^{23}$ se pueden entender las instituciones regionales como reglas, normas y prácticas que organizan y constituyen las relaciones sociales, creando restricciones $\mathrm{u}$ oportunidades para la agencia política en el ámbito de la coordinación de las relaciones de cooperación entre los países parte. En ese mismo sentido, la construcción de una institución es un proceso dinámico que, aunque tenga su origen marcado por expectativas específicas de los actores inicialmente presentes, se moldea a lo largo del tiempo a partir de consecuencias no intencionales ${ }^{24}$ de las decisiones y acciones de los agentes, reforzando la lógica institucional establecida, lo mismo que, por otro lado, mediante cambios graduales o de gran escala que dirigen la institución analizada hacia una nueva trayectoria. ${ }^{25}$

Es este proceso dinámico que determina las características institucionales y la capacidad de agencia de las instituciones regionales cuando reciben demandas. Frente a un contexto de crisis o de inseguridad acerca del futuro, en el que se tensio-

${ }^{23}$ Karl Fioretos, Tulia. G. Falleti y Adam Sheingate, "Historical Institutionalism in Political Science", en Fioretos, Falleti y Sheingate, op. cit.

${ }^{24}$ Paul Pierson, Politics in time: History, institutions, and social analysis, New Jersey, Princeton University Press, 2004.

${ }_{25}$ Paul Pierson y Theda Skocpol, "El institucionalismo histórico en la ciencia política contemporánea", Revista Uruguaya de Ciencia Política, 17, 1 (2008), pp. 7-38. 
nan las expectativas sobre el arreglo institucional establecido, las alternativas de respuesta de la institución son limitadas por su trayectoria. Denominado también por antecedentes críticos, la capacidad de respuesta de las instituciones, frente a contextos de coyuntura crítica, reflejan las alternativas disponibles para su agencia, ${ }^{26}$ que a su vez condicionan las posibilidades de reacción a una crisis nacional, regional o interna al mecanismo institucional, de modo que no hay una libre elección per se.

En otras palabras, es necesario identificar las variables que caracterizan los diferentes procesos del regionalismo sudamericano, que culminaron en la construcción y avance de las varias instituciones regionales a lo largo de la década de 2000, para comprender la manera en que éstas reaccionaron al periodo de crisis del regionalismo actual, lo mismo que frente al estímulo de la desintegración.

Antes de presentar lo que llamaremos ciclos del regionalismo, explicaremos las principales variables que caracterizan el regionalismo sudamericano y cómo éstas influyen en el desarrollo de esos procesos de integración, reflejando cómo las limitaciones institucionales conducen, como se apuntó anteriormente, a momentos de impulso o de retracción del apoyo gubernamental a la idea de integración regional.

La primera característica es la reducida interdependencia entre las economías sudamericanas. ${ }^{27}$ Desde la creación de la Comisión Económica para América Latina y Caribe (Cepal) al final de la década de 1940, sus trabajos elaboraron sobre las dificultades de las economías de los países sudamericanos para sostener ciclos de desarrollo, capaces de superar sus problemas estructurales. Al mismo tiempo, llamaron la atención respecto de la posibilidad de usar la integración como un instrumento de promoción de la industrialización y ampliación de

26 James Mahoney, "Path Dependence in Historical Sociology", Theory and Society 29, 4 (2000), pp. 507-548.

${ }^{27}$ Detlef Nolte, "The Pacific Alliance Regionalism without stress?”, en Nolte y Weiffen, op. cit., pp. 150-167. 
las exportaciones de manufacturas, aumentando el comercio intrarregional. Sin embargo, la realidad es que, a pesar de las distintas experiencias integracionistas impulsadas desde la década de 1960 en la región, éstas no fueron suficientes para cambiar significativamente la situación, como apuntan los datos presentados en el análisis de Marta Castilho ${ }^{28}$ sobre los países de la Asociación Latinoamericana de Integración (Aladi).

\section{Cuadro 1}

Evolución de la importancia del comercio intrarregional para el comercio exterior de los países de la Aladi, 1976-2009 (\% del total)

\begin{tabular}{lccc}
\hline & \multicolumn{3}{c}{ Peso del Aladi } \\
\cline { 2 - 4 } & Exportaciones totales & Importaciones totales & Comercio total \\
\hline $1962-1964$ & 7.7 & 10.0 & 8.7 \\
$1965-1969$ & 9.2 & 11.7 & 10.4 \\
$1970-1974$ & 11.1 & 11.2 & 11.1 \\
$1975-1979$ & 13.6 & 12.4 & 13.0 \\
$1980-1984$ & 11.6 & 14.3 & 12.6 \\
$1985-1989$ & 10.2 & 14.5 & 12.0 \\
$1990-1994$ & 14.4 & 14.9 & 14.6 \\
$1995-1999$ & 16.5 & 16.0 & 16.2 \\
$2000-2004$ & 12.5 & 14.5 & 13.4 \\
$2005-2008$ & 15.1 & 17.5 & 16.2 \\
2009 & 15.1 & 17.6 & 16.3 \\
\hline
\end{tabular}

Fuente: Comtrade, elaborado por Castilho, art. cit. p. 14.

Los datos apuntan a un crecimiento a partir de 1990, relacionado con la creación del Mercosur, que sin duda tuvo un papel significativo no sólo económicamente, sino también simbólicamente, porque involucró las dos principales economías de América del Sur (Argentina y Brasil), y por su capacidad de ejercer influencia sobre los demás países de la región. Los números del cuadro 1 confirman ese rol, mos-

${ }^{28}$ Martha Castilho, "Comércio Internacional e Integração Produtiva: uma análise dos fluxos comerciais dos países da Aladi”, Texto para Discussão IPEA 1705, enero de 2012, pp. 1-68. 
trando que después de cierta estabilidad, que perduró cerca de 20 años (1970-1989), el primer crecimiento ocurrió con la creación del Mercosur, para ganar un nuevo impulso en 1995, cuando concluyó el periodo de transición, y también a partir de 2005, con su relanzamiento bajo los gobiernos de Lula da Silva y Néstor Kirchner.

Estos impulsos integracionistas no fueron suficientes para cambiar las tendencias existentes en las economías sudamericanas, que dependen fuertemente del mercado internacional (ver gráfica 1), incluso de las inversiones extranjeras (ver cuadro 2). En realidad, el crecimiento económico de la Marea Rosa (2003-2013) no estuvo acompañado de un impulso industrializante, al contrario: estimuló la reprimarización de esas economías, apenas cambiando el centro de atracción de Estados Unidos por China.

\section{GRÁFICA 1}

Evolución del comercio regional y total de Aladi, 1962-2009 (en millones de dólares)

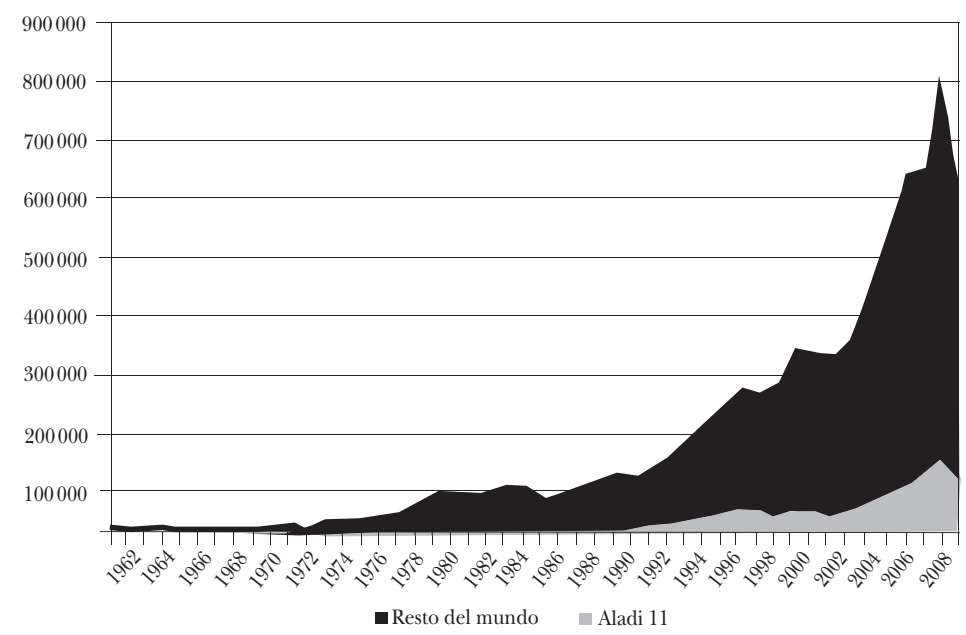

Fuente: Comtrade, elaborado por Castilho, art. cit., p. $15 .^{29}$

${ }^{29}$ Castilho art. cit., p. 15. 


\section{Cuadro 2}

América Latina y el Caribe: inversión extranjera directa neta $^{\mathrm{ab}}$ (en millones de dólares)

\begin{tabular}{lrrrrrrrrrr}
\hline & 1991 & 1992 & 1993 & 1994 & 1995 & 1996 & 1997 & 1998 & 1999 & $2000^{c}$ \\
\cline { 2 - 10 } América Lati- & & & & & & & & & & \\
na y el Caribe & 11066 & 12506 & 10363 & $\mathbf{2 3 7 0 6}$ & $\mathbf{2 4 7 9 9}$ & 39387 & $\mathbf{5 5 5 8 0}$ & 61596 & $\mathbf{7 7 0 4 7}$ & $\mathbf{5 7 4 1 0}$ \\
Argentina $^{\mathrm{d}}$ & 2439 & 3218 & 2059 & 2480 & 3756 & 4937 & 4924 & 4175 & 21958 & 5000 \\
Bolivia & 50 & 91 & 125 & 147 & 391 & 472 & 728 & 955 & 1015 & 730 \\
Brasil & 89 & 1924 & 801 & 2035 & 3475 & 11666 & 18608 & 29192 & 28612 & 30000 \\
Chile $^{\mathrm{e}}$ & 697 & 538 & 600 & 1672 & 2204 & 3445 & 3353 & 1842 & 4366 & -1130 \\
Colombia & 433 & 679 & 719 & 1297 & 712 & 2795 & 4894 & 2432 & 1135 & 985 \\
Costa Rica & 173 & 222 & 243 & 292 & 331 & 421 & 400 & 604 & 615 & 420 \\
Ecuador & 160 & 178 & 469 & 531 & 470 & 491 & 695 & 831 & 636 & 735 \\
El Salvador & 25 & 15 & 16 & $\ldots$ & 38 & $\ldots$ & $\ldots$ & 873 & 214 & 70 \\
Guatemala & 91 & 94 & 143 & 65 & 75 & 77 & 85 & 673 & 155 & 245 \\
Haitín & 14 & -2 & -2 & -3 & 7 & 4 & 4 & 11 & 30 & 5 \\
Honduras & 52 & 48 & 52 & 42 & 69 & 90 & 128 & 99 & 230 & 170 \\
México & 4742 & 4393 & 4389 & 10973 & 9526 & 9186 & 12830 & 11311 & 11568 & 13500 \\
Nicaragua & 42 & 42 & 40 & 40 & 75 & 97 & 173 & 184 & 300 & 335 \\
Panamá & 109 & 145 & 170 & 393 & 267 & 410 & 1256 & 1218 & 617 & 400 \\
Paraguay & 84 & 118 & 75 & 137 & 98 & 144 & 230 & 313 & 66 & 95 \\
Perú & -7 & 150 & 687 & 3108 & 2048 & 3242 & 1702 & 1860 & 1969 & 1185 \\
República & & & & & & & & & & \\
Dominicana & 145 & 180 & 189 & 207 & 414 & 97 & 421 & 700 & 1338 & 1005 \\
Uruguay & $\ldots$ & $\ldots$ & 102 & 155 & 157 & 137 & 113 & 155 & 225 & 180 \\
Venezuela & 1728 & 473 & -514 & 136 & 686 & 1676 & 5036 & 4168 & 1998 & 3480 \\
\hline
\end{tabular}

Fuente: Cepal. ${ }^{30}$

Notas: (a) Corresponde a la inversión directa en la economía declarante, deducida la inversión directa de residentes en el exterior. Para algunos países esta información no está disponible. Incluye la reinversión de utilidades; (b) Conforme la quinta edición del manual de Balanza de pagos del FMI, todas las transacciones entre empresas no financieras de inversión directa y sus empresas matrices y afiliadas se incluyen como inversión directa; (c) Cifras preliminares; (d) Esta partida para 1999 incluye el valor de la inversión de Repsol en Yacimientos Petrolíferos Fiscales. Parte de este monto corresponde a la compra de acciones de la empresa en poder de no residentes. El valor de esta última da origen, en la balanza de pagos, a un débito en la partida de inversión de cartera; (e) Desde 1995, esta partida contempla dos movimientos de apreciable valor. En 1999 incluye un ingreso por 9216 millones de dólares y una inversión en el extranjero por 4850 millones de dólares. En 2000 incluye una entrada por 3870 millones de dólares y una inversión en el exterior por 5000 millones de dólares; (f) Desde 1998 el Banco Central de Reserva de El Salvador cuenta con un registro sistemático sobre cifras de inversión extranjera directa.

30 Comisión Económica para América Latina, Cepal, Balance preliminar de las economías de América Latina y el Caribe, diciembre de 2000, LC/G.2123-P, p. 99. 
Aun reconociendo la influencia de los elementos sistémicos en los rumbos que tomó el regionalismo sudamericano y el rol que las potencias económicas ejercen sobre estos países, éstos no son suficientes para explicar la dificultad que la región enfrenta en la promoción de la integración. Sin embargo, nos ayudan a entender la dificultad para construir un liderazgo regional. Durante la primera década del siglo XxI, Brasil buscó ejercer un rol más protagónico en América del Sur, pero su capacidad de influencia se vio limitada por la creciente importancia económica y financiera de China en la región, durante el mismo periodo.

Los elementos sistémicos son factores de presión sobre las instituciones regionales sudamericanas, pero no explican las limitaciones de actuación y respuesta de éstas en un contexto crítico. Esta última está vinculada a otro factor: la fragilidad institucional de los procesos regionales sudamericanos. En otras palabras, la limitación para reaccionar cuando presionadas, garantizando no sólo un espacio para la convergencia de intereses y para atender a las expectativas, sino que un espacio de respuestas y actuación conjunta frente a problemas comunes.

De manera general, todas las experiencias comparten, en diferentes medidas, las características de reducida obediencia a las normas regionales, ${ }^{31}$ poca transparencia en los procesos de decisión, que permanecen dependientes de las voluntades políticas de los gobiernos nacionales, una burocracia que no garantiza la construcción de una memoria institucional y no es autónoma. ${ }^{32}$ A todos esos aspectos añadimos todavía una participación social muy restringida y

31 Stephanie Hoffmann y Frédéric Mérand, "Regional Organizations à la Carte: the Effects of Institutional Elasticity", en T. V. Paul, International relations theory and regional transformation, Reino Unido, Cambridge University Press, 2012.

32 Andrés Malamud y Gian Luca Gardini, "Has Regionalism Peaked? The Latin American Quagmire and its Lessons", The International Spectator (2012), 47, 1, pp. 116-133, https://doi.org/10.1080/03932729.2012.655013 
marginal, que no colabora para estimular el proceso de enraizamiento de la integración en la sociedad.

Los problemas institucionales están vinculados a una cuestión de principio para los países sudamericanos, y es el tema de la autonomía. En todos los gobiernos encontramos posiciones de resistencia a aumentar el poder de las instancias regionales, imponiendo siempre un límite al compromiso con la integración. ${ }^{33}$ Como lo reconoce Ocampo, ${ }^{34}$ "la situación se ve indudablemente afectada por un elemento de política y economía política: la resistencia de la mayoría de los países a ceder su soberanía económica a las organizaciones internacionales. [...] De hecho, fuera de la Unión Europea, los países no están dispuestos a ceder su soberanía ni a organizaciones regionales (y en la Unión Europea sólo en forma limitada)".35

En un espacio ya fragmentado, sin autonomía institucional ni liderazgos que incentiven o representen las nuevas expectativas existentes a partir del regionalismo, los procesos integracionistas sudamericanos encuentran límites estructurales para su consolidación. ${ }^{36}$ Este conjunto de factores acaba por limitar la capacidad de agencia de las instituciones frente a problemas comunes que surgen a lo largo del tiempo, reflejando la falta de estímulo, la parálisis o el desmantelamiento de las instituciones presentes en el escenario actual.

Vale destacar que los cambios de gobiernos y el creciente movimiento antiintegracionista, o de desintegración, amplían la presión frente a las instituciones regionales, ${ }^{37}$ dado

33 Víctor M. Mijares y Detlef Nolte,, "Regionalismo posthegemónico en crisis. ¿Por qué la Unasur se desintegra?”, Foreign Affairs Latinoamérica 18, 3 (2018), pp. 105-112.

34 José Antonio Ocampo, "Retomar la agenda del desarrollo", Revista de la Cepal 74 (2001), pp. 7-20.

35 Loc. cit.

36 Cintia Quiliconi y Raúl S. Espinoza, "Latin American Integration: Regionalism à la Carte in a Multipolar World?”, Colombia Internacional 92 (2017), pp. 1-41, https://doi.org/10.7440/colombiaint92.2017.01

37 Briceño Ruiz y Rivarola, art. cit. 
que el proyecto regional se forma y en parte depende de cómo los gobiernos perciben y gestionan las relaciones de cooperación en su entorno regional, pues en un momento apoyan instituciones regionales y en otro las desacreditan. ${ }^{38}$

La extensión del descrédito se muestra mayor cuando hay menos intereses económicos involucrados y menos participación social en la estructura institucional de la integración, como lo demuestran los casos del Mercosur y de la Unasur. En el primero, encontramos una estructura institucional compleja, en la cual están involucrados distintos actores (estatales y no estatales) que garantizan una dinámica mínima de funcionamiento, también en momentos de desinterés del Estado, lo que no se llegó a construir en el caso de la Unasur.

En el ámbito de la participación social, una de las principales banderas defendidas por los procesos vinculados a la idea del regionalismo posliberal era la democratización de los proyectos de integración. Según esa perspectiva, la integración debería superar la lógica del regionalismo abierto que había transformado la cuestión del desarrollo en simple apertura comercial, incorporando nuevos aspectos y, principalmente, nuevos actores. Para el regionalismo posliberal, la promoción de la equidad social, así como la superación de la pobreza y de la desigualdad, presuponen incorporar al proceso a aquellos grupos sociales excluidos en las experiencias integracionistas de la década de 1990.

Sin embargo, tanto el Mercosur como la Comunidad Andina (CAN) tuvieron desde el inicio instrumentos institucionales de acompañamiento a cargo de los congresos nacionales $y$, con el tiempo, fueron creando instancias de participación social e incorporando nuevos actores, más allá de los sectores económicos. Pero esos espacios de participación social son solamente consultivos y no participan del proceso decisorio.

El regionalismo posliberal estimuló una reformulación de esa realidad, impulsando cambios institucionales impor-

${ }^{38}$ Llenderrozas, Elsa, art. cit. 
tantes, como por ejemplo la transformación de la Comisión Parlamentaria Conjunta del Mercosur en el Parlamento del Mercosur (Parlasur), así como estimuló la implementación de las elecciones directas para los diputados del Parlamento Andino (Parlandino) por los gobiernos de los países de la CAN. En ambos casos, los parlamentarios no vieron significativamente alteradas sus competencias, al ser apenas representantes en organismos de consulta dentro de la integración.

De esta manera, podemos construir un cuadro con las características estructurales que constituyen la capacidad de acción y reacción de las instituciones regionales a las diferentes coyunturas que se presentan en el tiempo (cuadro 3).

\section{CuAdro 3}

Características estructurales de las instituciones regionales sudamericanas

\begin{tabular}{|l|c|c|c|}
\hline \multirow{2}{*}{ Antecedentes críticos } & \multicolumn{3}{c|}{ Bloques regionales } \\
\cline { 2 - 4 } & Mercosur & Unasur & CAN \\
\hline Influencia de un liderazgo regional & Mediano & Alto & Bajo \\
\hline Interdependencia económica & Mediana & Baja & Baja \\
\hline Institucionalidad & Alta & Baja & Alta \\
\hline Autonomía del bloque & Baja & Baja & Mediana \\
\hline Participación social & Mediana/alta & Baja & Mediana \\
\hline Obediencia a las normas regionales & Mediana & Baja* & Mediana \\
\hline Intereses comerciales & Altos & Bajos & Medianos \\
\hline Convergencia política & Alta & Alta & Baja \\
\hline
\end{tabular}

Fuente: elaboración propia.

* En Unasur la incorporación de las normas acordadas es voluntaria, por lo tanto, es difícil medir su cumplimiento.

Las características presentadas en el cuadro 3 representan los antecedentes críticos de los procesos regionales sudamericanos. Así como lo plantearon los teóricos del instituciona- 
lismo histórico, ${ }^{39}$ en momentos de crisis o de tensionamiento de las expectativas futuras de la institucionalidad presente, son los antecedentes críticos los que limitan o configuran las posibles decisiones. En otras palabras, factores de estrés en un contexto crítico no llevan directamente a la desintegración. La resiliencia de las instituciones depende de sus antecedentes críticos, es decir, de las características internas del proceso constituido. ${ }^{40}$

Como puede verificarse en el cuadro comparativo, hay una conexión entre la participación social y la presencia del comercio o de intereses económicos frente al bloque regional. Mientras el Mercosur fue considerado un proyecto preso de la lógica del regionalismo abierto de los años 1990 y, de esta manera, con un fuerte arraigo del tema del comercio, la Unasur se construyó bajo el signo del regionalismo posliberal, para el cual la integración no debería estar vinculada a la lógica comercial, sino a la construcción de un regionalismo multidimensional.

Esa diferenciación entre los dos procesos explica por qué un mismo contexto produjo resultados tan distintos. Se atribuye la desconstrucción de la Unasur a los problemas políticos generados por la presencia de Venezuela, aun si también está presente en el Mercosur. Los cambios políticos son otro ejemplo al que se recurrió para explicar el ocaso del regionalismo posliberal, pero la capacidad de desmantelamiento se mostró más eficaz en el caso sudamericano que en el Cono Sur (es decir, Chile, Paraguay, Uruguay y Argentina).

Lo mismo ocurre con el gobierno brasileño de Jair Bolsonaro, que diversas veces ha indicado su insatisfacción con el Mercosur y su intención de reformular ese proceso, su capacidad de concretar sus amenazas se muestra mucho más limitada en ese caso, en parte debido a las resistencias que

${ }^{39}$ Dan Slater y Erica Simmons, "Informative Regress: Critical Antecedents in Comparative Politics", Comparative Political Studies, 43, 7 (2010), pp. 886-917, https://doi.org/10.1177/0010414010361343

${ }^{40}$ Weiffen, Brigitte. art. cit. 
distintos grupos económicos y sociales presentan frente a la voluntad gubernamental. En las próximas secciones de este artículo apuntamos cómo la propia lógica de esos procesos integracionistas, en particular de Unasur, resultan en estructuras institucionales limitadas en su acción y decisión, estimulando los ciclos sucesivos de apoyo y desgaste del regionalismo.

\section{El CASO DE UNASUR}

Creada en 2008, la Unasur configuró el intento de articular países subdesarrollados a través de la convergencia de sus intereses y expectativas frente al entorno regional. Según su tratado constitutivo, la Unasur tendría como objetivo "construir, de manera participativa y consensuada, un espacio de integración y unión en el ámbito cultural, social, económico y político entre sus pueblos". ${ }^{41}$ Sin embargo, y aunque propusiera construir una identidad y ciudadanía suramericana, la propia estructura institucional de Unasur contradecía su propuesta de buscar fortalecer la unidad de América Latina y el Caribe.

Como una institución intergubernamental, el órgano máximo de Unasur fue el Consejo de Jefas y Jefes de Estado y de Gobierno (CJEG), cuyo rol era establecer lineamientos políticos, proyectos, programas y planes de acción, en conjunto con la presidencia pro tempore (PPT), ejercida anualmente por uno de los Estados miembros. Además del CJEG, la Unión estaba compuesta por el Consejo de Ministras y Ministros de Relaciones Exteriores (CMRE), el Consejo de Delegadas y Delegados (CDD), la Secretaría General (SG) y 12 Consejos Sectoriales. A pesar de que el Parlamento Sudamericano estaba

41 Tratado Constitutivo da União de Nações Sul-Americanas - Brasília, 23 de mayo de 2008, Unasur, 2008, http:/ / www.itamaraty.gov.br/images/ ed_integracao/docs_UNASUL/TRAT_CONST_PORT.pdf (consulta del 20 de octubre de 2020). 


\section{previsto en el Tratado Constitutivo de Unasur, el mecanismo no entró en vigor hasta el desmantelamiento del organismo en 2019 (véase la imagen 1). ${ }^{42}$}

\section{IMAGEN 1 \\ Organigrama de la estructura institucional de Unasur}

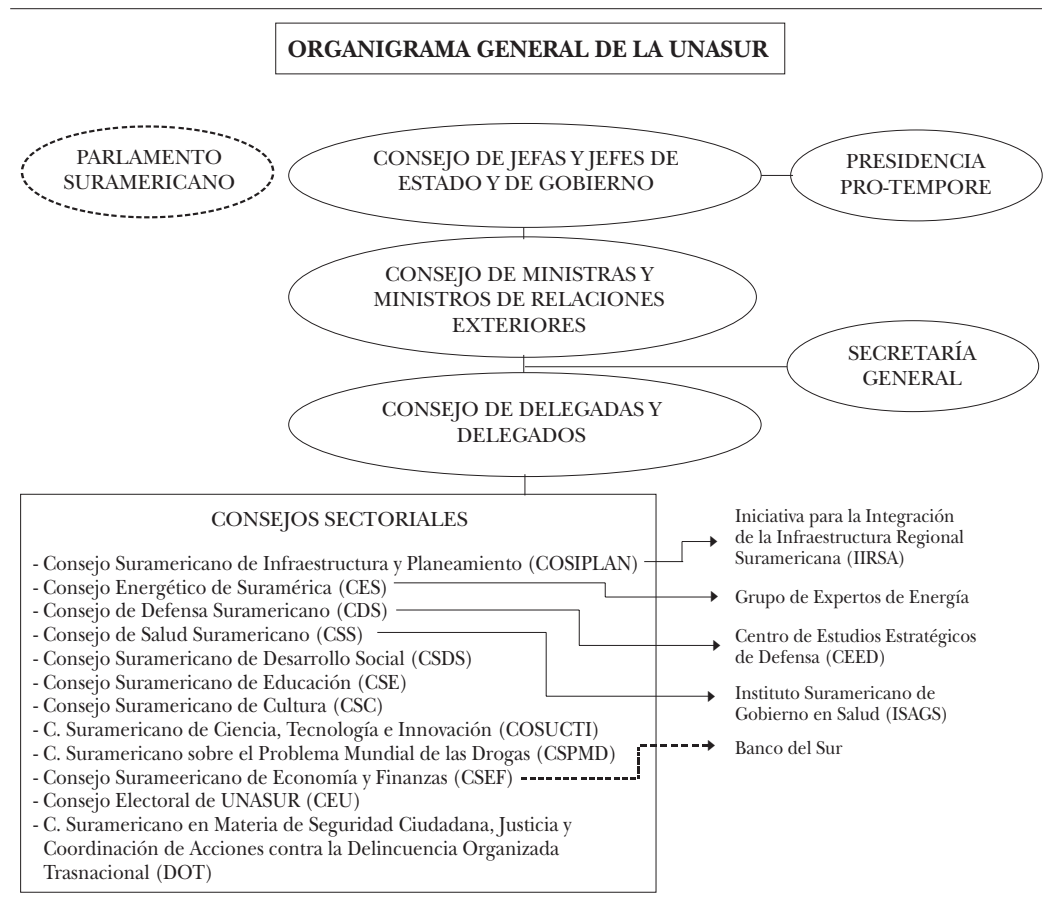

Fuente: Ruvalcaba, art. cit., p. 179.

42 D. M. Ruvalcaba, "Institucionalidad de la Unión de Naciones Suramericanas (Unasur): Balance de su primera década de existencia, 2008-2017”, en J. A. P. Coronado et al., Dimensiones, estrategias y alternativas de la integración autónoma para América Latina y el Caribe. Desafíos para el caso mexicano (2010-2015), Tomo II, Guadalajara, Conacyt, Red de Investigación sobre la Integración de América Latina y el Caribe (Redialc), 2018, pp. 177-198. 
A pesar de una larga estructura, apoyada no solamente por la PPT, sino también por el Secretario General -que tenía bajo su capacidad la ejecución del mandato de los órganos de Unasur, así como la preparación de su presupuesto anual y otros reportes institucionales- en los 10 años de su existencia muchas fueron las barreras a ser superadas y pocos los logros alcanzados. Además, a lo largo de este periodo, se ilustra la problemática concentración del poder de decisión en los representantes designados por los gobiernos sudamericanos para el desarrollo y avance de esta institución regional.

Esta barrera estructural se configuró como un factor de desintegración a partir de 2017, con la parálisis de las cumbres anuales de Unasur frente al bloqueo de la candidatura argentina para el puesto de Secretario General por Venezuela, Bolivia, Surinam y Ecuador, de modo que la organización estuvo sin un secretario designado desde el 31 de enero de 2017.

En la perspectiva institucionalista, frente a un contexto crítico marcado por varias crisis: la nacional venezolana, la económica argentina y la política brasileña -posterior al impeachment- y su consecuente alejamiento del papel de protagonista que había tenido en las décadas anteriores en el regionalismo sudamericano, la Unasur estaba limitada institucionalmente para responder a las nuevas demandas nacionales y regionales de sus países miembros. ${ }^{43}$

Como uno de sus antecedentes críticos, la Unasur tenía -como ya se ha apuntado en el cuadro 3-, una fuerte dependencia de un liderazgo regional para el avance y mantenimiento del bloque, sumado a un bajo nivel de intereses económicos compartidos, una burocracia limitada y alta dependencia de intereses políticos convergentes para su manutención. De esa manera, la coyuntura crítica marcada por el alejamiento brasileño y venezolano -los principales liderazgos en la creación del bloque-y por el fin de la convergencia política a partir de las elecciones de gobiernos de derecha

${ }^{43}$ Comini y Frenkel, art. cit. 
en la segunda década del siglo xxi, configuró un contexto en el cual la estructura existente no fue suficiente para sostener las expectativas y los intereses de los Estados sudamericanos respecto al regionalismo.

La baja capacidad de agencia y mantener el diálogo sin el impulso de los gobiernos limitó su capacidad de respuesta para enfrentar las nuevas condiciones, cuyas demandas no fueron atendidas en el corto plazo. De esa manera, lo que se apunta es que el desmantelamiento de Unasur no se configura simplemente como resultado de los cambios sistémicos del periodo, sino que es un reflejo de su trayectoria institucional y de sus antecedentes críticos.

En ese sentido, el contexto histórico es la oportunidad para el proceso de la desintegración regional, no su causa. Las limitaciones institucionales, resultantes de la trayectoria del regionalismo sudamericano, refuerzan una dinámica dependiente directamente de cómo cada gestión gubernamental de los países sudamericanos se incorpora a la integración regional y a su entorno geográfico.

Por lo tanto, así como apuntan Ruvalcaba ${ }^{44}$ y Arroyave Quintero, ${ }^{45}$ además de que la concentración poder de decisión es histórica -y común a todos los procesos de integración en América del Sur-representa un gran desafío al intento de construir organismos latinoamericanos autónomos, que representen un contrapeso a los gobiernos y sus decisiones, principalmente para romper el ciclo de impulso y falta de estímulo de la cooperación y de la integración.

${ }^{44}$ Loc. cit.

45 Mario Arroyave Quintero, "La Unasur en la estrategia regional de Colombia y Brasil”, en E. Pastrana Buelvas, S. Jost y D. Flemes (eds.), Colombia y Brasil: ¿̨socios estratégicos en la construcción de Suramérica?, Bogotá, Pontificia Universidad Javeriana/Fundación Konrad Adenauer, 2012, pp. 239-282. 
Considerando las características indicadas, entre éstas el interpresidencialismo, ${ }^{46} \mathrm{Pozo}^{47}$ indica que la inexistencia de un proyecto común compartido entre los países, así como la falta de cumplimiento de las normas establecidas y la insuficiente o reducida interdependencia económica, dan lugar a que el regionalismo sudamericano pase por una alternancia entre periodos de elogio y cuestionamiento. El proceso cíclico se configura por una fase inicial de entusiasmo político y normativo, seguida de una fase de crisis y acusación de retórica, ineficacia e ideologización. A su vez, este proceso cíclico acaba por generar lo que el autor va a llamar de los "muertos vivientes de la integración latinoamericana" ${ }^{48}$ como Unasur.

Además, no avanza la participación social en los procesos regionales, que podría ampliar el reconocimiento y la demanda de estos espacios por la sociedad civil. La preocupación con la democratización estaba presente en el proyecto de la Unasur que pretendía establecer tanto un parlamento regional, como una instancia para la participación social. En el primer caso, la implantación de un parlamento exclusivo encontró resistencias de los gobiernos, especialmente por las implicaciones políticas y económicas.

Para los países miembros de la Unasur que participaban del Mercosur o de la CAN, la creación de un nuevo parlamento regional podría significar una duplicidad en la representación parlamentaria regional, ya que poseían representantes en el Parlasur o en el Parlandino, y no había interés en crear más costos para mantener otra instancia legislativa regional. Inicialmente se propuso fundir los dos parlamentos para formar el de la Unasur, pero esa idea fue abandonada y se pensó en permitir que los diputados que participaban del Parlasur y

46 Andrés Malamud, "Presidential Diplomacy and the Institutional Underpinnings of Mercosur: an Empirical Examination”, Latin American Research Review, 40, 1 (2005), pp. 138-164, https://doi.org/10.1353/ lar.2005.0004

${ }^{47}$ Pedro Caldentey del Pozo, "El regionalismo a examen. La crisis global de la integración", Revista de Fomento Social, 74, 3 (2020), pp. 349-368.

48 Ibid., p. 360. 
el Parlandino pudieran también representar sus naciones en la Unasur. Nunca se llegó a un consenso sobre el proyecto definitivo del protocolo adicional para la creación definitiva de ese parlamento suramericano.

Al final, esa cuestión fue superada por la crisis de Unasur. Cuando se concluyó la construcción de lo que sería la sed de su parlamento (en la ciudad de San Benito, Departamento de Cochabamba-Bolivia), el proceso integracionista ya estaba paralizado por las discordancias internas para elegir al nuevo secretario general, en una disputa entre los países que todavía apoyaban a Venezuela y aquellos contrarios al gobierno del presidente Maduro.

En lo que respecta a la participación social, solamente en 2013 se creó el Foro de Participación Social de la Unasur, de carácter consultivo y no vinculante, es decir, sus decisiones no eran necesariamente incorporadas por los órganos decisorios de la integración. El Foro empezó a funcionar apenas en agosto de 2014, sin llegar a tener un papel relevante en la dinámica de la Unasur, dado que poco tiempo después se iniciaron los conflictos internos que llevaron a su desmantelamiento.

De esa manera, en este artículo discutimos que el desmantelamiento de Unasur no se configura simplemente como resultado de los cambios sistémicos del periodo, sino que refleja la trayectoria institucional establecida. En esta argumentación presentamos algunos de los aspectos centrales de la construcción del bloque así como de los consejos de Unasur que demostraron más avances en el periodo: el Consejo de Defensa Sudamericano (CDS), el Consejo Suramericano de Salud (CSs) ${ }^{49}$ y, de manera más puntual, uno que demostró resiliencia en periodos de inestabilidad en la región: el Consejo Sudamericano de Infraestructura y Planeamiento (Cosiplan). ${ }^{50}$

${ }^{49}$ Lucas Eduardo Silveira de Souza, "O Brasil e o regionalismo sul-americano: o papel da Unasul na política externa do governo Rousseff (20112016)", tesis de maestría en Relaciones Internacionales, Universidade de Brasília, 2018, pp. 155, https://repositorio.unb.br/handle/10482/34899

${ }^{50}$ Bárbara C. Neves, "Política externa brasileira e a integração da infraestrutura na América do Sul: uma análise a partir dos mecanismos iirsa/ 
El Consejo de Defensa Sudamericano (CDs), creado en 2008, representó el intento de los países de la región para solucionar sus propios problemas sin la intervención de actores externos, con un rol importante en diferentes conflictos en la región. El cos estableció un marco de coordinación, cooperación e integración en materia de defensa exclusivamente sudamericana, sin embargo, el Consejo no logró superar el desmantelamiento de Unasur. ${ }^{51}$

Desde su creación, el CDS resultó en importantes avances para la seguridad y defensa sudamericana. A partir de los esfuerzos conjuntos y espacios de diálogo establecidos, el CDs fue un marco ${ }^{52}$ para la coordinación, cooperación e integración en temas de defensa desde una perspectiva estrictamente subregional, ocupando el espacio que tenía antes, de forma prominente, la Organización de los Estados Americanos (OEA). ${ }^{53}$

De manera general, el cDs demostró, en poco menos de 10 años, que había no sólo demanda para que los problemas sudamericanos fueran resueltos por la región, sino que los países de América del Sur tenían la capacidad de resolver sus problemas sin intervención de actores extrarregionales. Como marco de su potencial, desde 2008, el cDs tuvo una actuación muy importante en la mediación y resolución del conflicto entre Ecuador y Colombia, frente al asesinato de guerrilleros de las Fuerzas Armadas Revolucionarias de Colombia (FARC) por militares colombianos en territorio ecuatoriano. Además, así como lo presentaron Teixeira Jr. y

cosiplan" (tesis de Maestría en Relaciones Internacionales - UnESP/UNICAMP/PUC-SP), Programa San Tiago Dantas de Pós-graduação em Relações Internacionais, São Paulo, 2019, 249, http:/ / hdl.handle.net/11449/181007

${ }^{51}$ Loc. cit.

52 Thomas Legler, "Post-hegemonic regionalism and sovereignty in Latin America: optimists, skeptics, and an emerging research agenda", Contexto internacional, 35 (2013), pp. 325-352, https://doi.org/10.1590/ S0102-85292013000200001

53 Andrés Serbin, "América del Sur en un mundo multipolar: ¿es la Unasur la alternativa?”, Nueva Sociedad (2009), p. 219. 
Lucena Silva, ${ }^{54}$ el CDS se constituyó en un mecanismo para gestionar el orden regional de seguridad, superando, en parte, la competencia estratégica existente, así como proporcionando un espacio para el control del rearme en el subcontinente.

Aun así, vale apuntar que durante el ápice de la tensión de las instituciones regionales, el cDS no fue capaz de responder a las demandas, al no presentarse como un espacio para el diálogo propositivo frente a la crisis venezolana. De alguna manera, la propia limitación institucional del cDs para la resolución de la crisis política y económica en Venezuela se configuró como un factor de descrédito del bloque, una vez que las expectativas referentes a los ámbitos de seguridad y defensa no se alcanzaron en un contexto en el cual se exigía de la institución.

A su vez, el Consejo Sudamericano de Salud (css) creado también en 2008, resultó del intento regional de coordinar normas, procedimientos y estándares de acción en el ámbito de la salud y en el combate a las epidemias de manera conjunta. La creación del Instituto Sudamericano de Gobierno en Salud (Isags) fue el marco de ese proceso, y tenía como una de sus directrices centrales superar el acceso desigual a medicamentos en las naciones más pobres, además del desarrollo de estudios, artículos y libros acerca de la cuestión de vigilancia sanitaria, epidemiológica y ambiental. ${ }^{55}$ Sin embargo, y a pesar de que estos mecanismos representaran un impulso hacia una gobernanza sudamericana en salud, en los últimos años fueron totalmente destruidos. ${ }^{56}$

${ }^{54}$ Augusto W. M. Teixeira Júnior y Antonio H. Lucena Silva, "Explaining Defense Cooperation With Process-tracing: The Brazilian Proposal for the Creation of Unasur South American Defense Council", Revista Brasileira de Política Internacional 60, 2 (2017), pp. 1-18.

${ }^{55}$ Loc. cit.

${ }^{56}$ Pía Riggirozzi, "Coronavirus y el desafío para la gobernanza regional en América Latina”, Análisis Carolina-Fundación Carolina, 12 (2020). 
En el caso del Consejo Suramericano de Infraestructura y Planeamiento (Cosiplan), creado en 2009, Barbara C. Neves ${ }^{57}$ apunta que hubo un importante incremento de las inversiones en infraestructura en el continente a partir de la realización de obras de la cartera de proyectos del Cosiplan en el periodo 2011-2018. Sin embargo, tal impulso, lo mismo que con el avance de las crisis en Latinoamérica, no refleja puramente lo sucedido en Unasur, sino que parte de la trayectoria institucional de la IIRSA ${ }^{58}$ del interés de diversos actores económicos nacionales, regionales y extrarregionales, y de la actuación de su Comité Coordinador Técnico (CCT), formado por el Banco Interamericano de Desarrollo (BID), la Corporación Andina de Fomento (CAF) y el Fondo Financiero para el Desarrollo de la Cuenca del Plata (Fonplata). Además, como se discutirá más adelante, la cuestión clave a destacar de este consejo fue la actuación de Brasil y de sus inversiones en obras de carácter nacional que dieron forma a la cartera de proyectos de integración de infraestructura.

De esa manera, puede afirmarse que, aunque se haya configurado como un modelo de integración sudamericano con sus propias características y resultados diversos, las debilidades de Unasur para cumplir con las promesas hechas en 2008 fueron varias. ${ }^{59} \mathrm{La}$ flexibilidad institucional, a pesar de posibilitar diferentes caminos e incorporación de pautas en la agenda regional, resultó en estructuras "débiles y supeditadas a los intereses nacionales" ${ }^{60}$ Como condicionante política, la institucionalidad limitada no solamente es uno de los factores de la parálisis y desmantelamiento de Unasur en los últimos años de la segunda década del siglo xxı, tanto como su lapso de autonomía resultó en la contradicción de su proceso de creación, una vez que el movimiento posliberal defendió

${ }^{57}$ Neves, op. cit.

58 La IIRsa fue incorporada al Cosiplan como su foro técnico en 2011, que pasó a actuar bajo el régimen de Unasur.

59 Detlef Nolte y Nicolás Matías Comini, "Unasur: Regional Pluralism as a Strategic Outcome", Contexto Internacional 38, 2 (2016).

${ }^{60}$ Ruvalcaba, art. cit., p. 195. 
la inclusión social y democrática en las instituciones regionales, aspecto que nunca se desarrolló plenamente en Unasur.

\section{El rol de la infraestructura en el proceso de integración sudamericano}

Al contrario del caso general de Unasur, el análisis de las iniciativas para el desarrollo de la infraestructura regional se presenta como un punto clave para comprender cómo las características de los procesos regionales, además de los actores y las expectativas presentes, configuran la capacidad institucional del proceso para responder a las demandas existentes y, de esa manera, posibilitar que éste se sostenga a lo largo del tiempo, como se discutirá en esta sección.

Desde la década de 2000, se considera la infraestructura como un aspecto esencial para el avance de la integración latinoamericana, principalmente en el ámbito del comercio intrarregional. ${ }^{61}$ En 2008, ese entendimiento fue reforzado con la creación de Unasur, que en el tratado de su constitución señaló la priorización de, entre otras cosas, la infraestructura ${ }^{62}$ Desde 2011, con la incorporación de IIRsA al Cosiplan, hasta 2018, el consejo se destacó por aún mantenerse activo en medio de la tensión de las instituciones regionales y de la propia Unasur. De hecho, en el periodo se concretaron 127 obras de su cartera de proyectos, con más de 58000 millones de dólares invertidos en la región, valor ocho veces mayor que en la década anterior. ${ }^{63}$

Sin embargo, estos logros no reflejan solamente las oportunidades generadas por los procesos de integración lati-

${ }^{61}$ Iniciativa para la Integración de la Infraestructura Regional Suramericana (iirsa), 10 años después: sus logros y desafíos, Comité de Coordinación Tecnica (cct) y Secretaría del cct, Buenos Aires, Documentos iirsa, diciembre de 2011, http://www.iirsa.org/BancoMedios/Documentos20PDF/lb_ iirsa_10_anios_sus_https://www.iirsa.org/Document/Detail?Id=3356

62 Tratado Constitutivo..., op. cit.

63 Neves, op. cit. 
noamericanos, sino que representan dos especificidades institucionales de los organismos del subcontinente. En primer lugar, el avance de las obras de infraestructura en el continente simboliza la trayectoria de IIRSA, los intereses económicos detrás del tema y el mantenimiento de las actividades desde su núcleo funcional, el CCT, como ya se ha mencionado, formado por el BID, CAF y Fonplata. ${ }^{64}$ A pesar de cambios en las políticas regionales, resultando por momentos en el estímulo a la participación, y en otros en el alejamiento de los Estados de Unasur, los miembros del cCT se articularon constantemente con las iniciativas regionales, sea por medio de sus aportes, produciendo estudios de factibilidad de obras, reportes anuales, así como participando en las reuniones del mecanismo. ${ }^{65}$

La participación de los equipos técnicos del cCT resultó en un impulso institucional de la IIRsA durante los años del Cosiplan, que también facilitó en muchos momentos la captación de recursos para la región. ${ }^{66}$ Mientras tanto, a lo largo de esos años, ocurrió la obstrucción de premisas apoyadas por el CCT por países clave en el proceso, específicamente Brasil, "como la profundización institucional del mecanismo y la creación de marcos regulatorios y jurídicos que garantizarían estabilidad y seguridad a los posibles inversores en los proyectos". ${ }^{67}$

De esa manera, la segunda especificidad se construye frente al uso del espacio regional latinoamericano para impulsar intereses nacionales brasileños, ${ }^{68}$ cuyo resultado fue la cons-

${ }^{64}$ Karen dos Santos Honório, "Política regional e projeção de interesses privados: Problematizando a América do Sul nos governos Lula”, Carta Internacional, 14, 3 (2019), https://doi.org/10.21530/ci.v14n3.2019.968

65 Neves, op. cit.

66 Leandro F. Couto, "A Iniciativa para a Integração da Infra-estrutura Regional Sul-americana - IIRSA como instrumento da política exterior do Brasil para a América do Sul”, OIKOS (Río de Janeiro), 5, 1, (2008), http://www.revistaoikos.org/seer/index.php/oikos/article/view/109

67 Neves, op. cit., p. 213 (traducción del editor).

68 Amanda C. Barrenengoa, "De la unidad suramericana a la fragmentación regional: contradicciones en la Unasur a partir de las políticas de los gobiernos lulistas y las tensiones con las clases dominantes", Conjuntura Austral, 1, 56 (2020), pp. 77-93. 
trucción de organismos regionales flexibles y dependientes del activismo de los gobiernos de los países miembros, manteniendo la autonomía nacional de decisión en detrimento de la autonomía de los espacios regionales. Al inicio de la década de 2000 y de la creación de IIRSA, el proyecto de integración presentaba como argumento la importancia de obtener inversiones privadas que ampliarían la autonomía de los Estados en el ámbito de la infraestructura, sin demandar de ellos apoyo financiero para que no hubiera limitaciones al proyecto frente a los problemas fiscales de los países. ${ }^{69}$

\section{GrÁFICA 2}

Inversión en las obras concluidas de la cartera Cosiplan, 2011-2018 (valores en dólares)

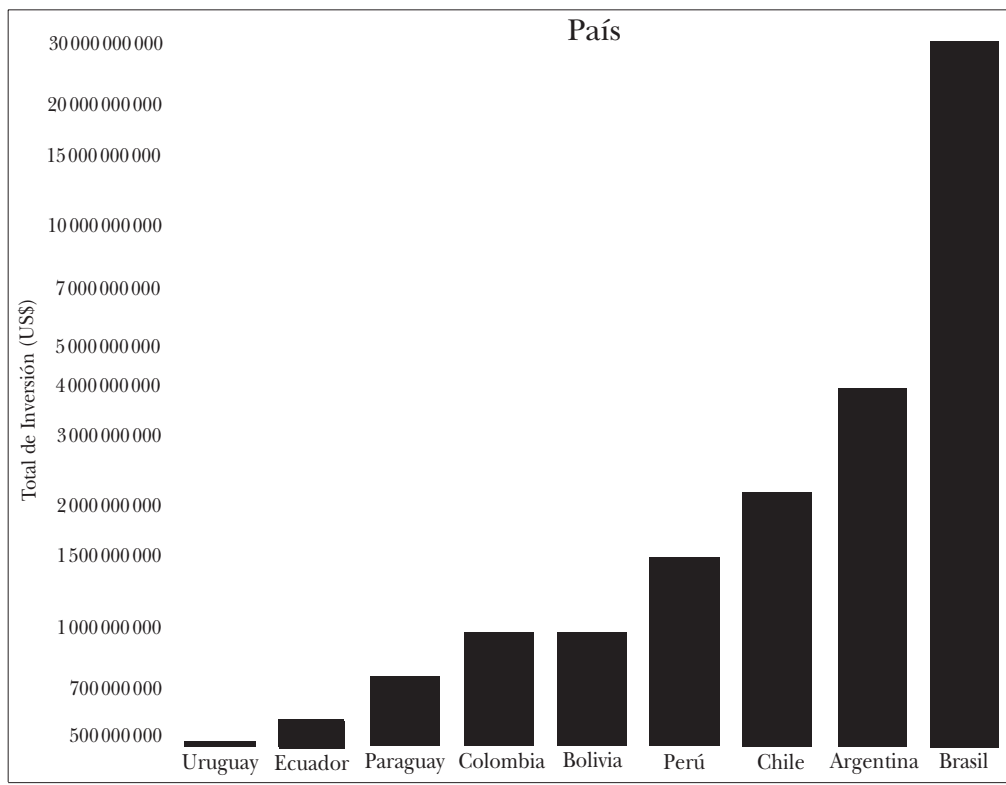

Fuente: elaboración propia con datos del $\operatorname{sip}^{70}$ de IIRSA.

${ }^{69}$ Couto, art. cit.

${ }^{70}$ El Sistema de Información de Proyectos (SIP) de IIRSA está disponible en http://www.iirsa.org/proyectos (consulta del 26 de octubre de 2020). 
Sin embargo, a lo largo de la segunda década del siglo xxI, los proyectos que fueron concluidos entre 2011 y 2018 tuvieron una gran participación de inversiones provenientes del presupuesto nacional de los países sudamericanos, en especial de Brasil. Del total invertido para las 127 obras concluidas en el periodo en el marco de Cosiplan, por más de 58000 millones de dólares, como ya habíamos apuntado, Brasil utilizó más de 28000 millones para obras en su propio territorio (véase la gráfica 2) y, de este valor, casi 21000 millones de dólares fueron aportados por el tesoro nacional brasileño (véase el cuadro 3).

\section{CuAdro 4}

Fuentes de inversión de las obras concluidas

de la cartera Cosiplan, 2011-2018

(valores en dólares)

\begin{tabular}{|l|r|}
\hline Tesoro Nacional (Brasil) & 20999144214 \\
\hline Binacional & 17408800000 \\
\hline Privado & 630605497 \\
\hline Tesoro Nacional (sin Brasil) & 411430970 \\
\hline Varios & 1731158974 \\
\hline CAF & 1409287411 \\
\hline BID & 1270951766 \\
\hline FOCEM & 419300000 \\
\hline Tesoro Municipal (São Paulo, Brasil) & 300000000 \\
\hline Público & 180000000 \\
\hline BNDEs & 157100000 \\
\hline EU & 86348668 \\
\hline Banco Mundial & 56000000 \\
\hline Fonplata & 503477 \\
\hline
\end{tabular}

Fuente: elaboración propia con base en información del SIP de IIRSA.

La destacada participación brasileña en la IIRSA/Cosiplan se formó mediante la inclusión de proyectos nacionales de infraestructura que ya integraban otras carteras de desarrollo de infraestructura del país, como el Programa de Acelera- 
ción del Crecimiento (PAC). A su vez, ese aspecto contradice la premisa central del mecanismo, de priorizar la identificación de obras de interés bilateral y subregional. ${ }^{71}$ De manera más detallada, y de acuerdo con los datos del Sistema de Información de Proyectos (SIP) de IIRsA, de 2000 a 2010, de los 33 proyectos concluidos, apenas seis eran bilaterales, y de 2011 a 2018, de los 127 proyectos concluidos, apenas 17 eran bilaterales.

Además, como apunta Neves, ${ }^{72}$ aunque gran parte de los proyectos nacionales que integraron la cartera de IIRSA/Cosiplan demostraron en sus objetivos la conexión con los ejes de integración de la iniciativa, es evidente que muchos no estaban relacionados con la integración del espacio regional, al haber una correlación directa con intereses nacionales, ${ }^{73}$ como puede verse en el Proyecto de la Ferrovía Norte-Sur Fase II (Açailândia-Palmas). En su objetivo consta que "la EF-151, Ferrovía Norte-Sur (FNS), fue proyectada para promover la integración nacional, minimizar costos de transporte y vincular las regiones brasileñas [...]".74

Esta realidad señala la fragilidad de los mecanismos regionales que están siempre condicionados por las dinámicas nacionales, principalmente a partir de 2014 con la Operación Lava Jato en Brasil, visto que muchas de las obras que formaron parte de la cartera de IIRSA/Cosiplan fueron sobrevaloradas y estuvieron marcadas por problemas de corrupción, no sólo en Brasil, sino también en otros países sudamericanos.

${ }^{71}$ Iniciativa para la Integración de la Infraestructura Regional Suramericana (IIRSA), Declaração de Brasília, Documentos IIRSA, diciembre de 2000, http://www.iirsa.org/admin_iirsa_web/Uploads/Documents/co municado_brasilia_esp.pdf

${ }^{72}$ Neves, op. cit.

${ }^{73}$ Karen dos Santos Honório, "A política das obras e as obras da política: Um estudo sobre as relações bilaterais Brasil-Bolívia e Brasil-Equador na dimensão da infraestrutura nos governos Lula da Silva (2003-2010)", tesis de doctorado, Programa de Pós-Graduação em Relações Internacionais San Tiago Dantas, unesp, Unicamp, puc-sp, 2019, https://reposito rio.unesp.br/handle/11449/182283

${ }^{74}$ Neves, op. cit., p. 168 (traducción del editor). 
Además, la mala distribución de recursos en la región, en la que Brasil es el país con mayor capital y capacidad de concretar obras, acaba por profundizar las asimetrías entre los países sudamericanos, creando tensión en las expectativas y motivaciones frente al proyecto regional. ${ }^{75}$

En resumen, la primera especificidad se refiere al avance de un mecanismo como consecuencia de su trayectoria institucional y de los intereses detrás de éste, que de alguna manera se relaciona con el ideal integracionista de estas instituciones y de los actores económicos interesados, y no necesariamente representa el ideal integracionista de los gobiernos sudamericanos al inicio del siglo; y eso si es que puede decirse que algún día existió un proyecto de integración común en la región. En cambio, la segunda es una paradoja que se refiere a la característica intergubernamental del regionalismo latinoamericano frente al uso de la región y de los procesos integracionistas para apalancar intereses nacionales específicos, ${ }^{76}$ lo cual acaba, a lo largo del tiempo, actuando en sentido contrario de las premisas regionalistas acordadas al inicio. Es decir, se estimula un espacio de integración que al final será desmantelado, cuando ya no sirve para los propósitos nacionales que llevaron a su creación, de modo que la autonomía nacional siempre es prioridad en detrimento del espacio regional. ${ }^{77}$

A su vez, la IIRsA, así como los intereses detrás de ésta, se mantienen, si bien están en medio de este escenario de desintegración de Unasur y de la parálisis del Cosiplan. Su trayectoria institucional, principalmente a través de la participación del CCT (BID, CAF y Fonplata) y del continuo interés económico de actores nacionales de los países sudamericanos, propició que el mecanismo no dependiera del aparato institucional de Unasur/Cosiplan para seguir con sus actividades.

75 Amanda C. Barrenengoa, "¿Territorialidad neoliberal? Las políticas de desarrollo e integración física en tiempos del lulismo", Geograficando, 16, 1 (2020), pp. 1-14.

${ }^{76}$ Honório, art. cit.

${ }^{77}$ Barrenengoa, "De la unidad suramericana...", art. cit. 
En agosto de 2020 el BID, la CAF y el Fonplata anunciaron el lanzamiento de la Alianza para la Integración y Desarrollo de América Latina y el Caribe (Ilat), destacando que su objetivo es ofrecer apoyo técnico y financiero para proyectos de integración en el continente. ${ }^{78}$ La Ilat presenta ya una cartera de proyectos en ejecución que pasa a incorporar países de Latinoamérica y del Caribe que antes estaban excluidos de Unasur, además de dar continuidad a algunos proyectos de la Cartera IIRSA/Cosiplan, como por ejemplo, el financiamiento de la construcción de la "Segunda línea de 500 kw Yacyretá-Villa Hayes", ${ }^{79}$ en Paraguay.

En este sentido, al mismo tiempo que el desmantelamiento de Unasur paralizó el espacio institucional del Cosiplan, al no haber más reuniones desde diciembre de 2017, lo cual resultó en una cartera de proyectos desactualizada desde marzo de 2018, los actores, intereses económicos presentes y la institucionalidad resultante del trabajo conjunto de los bancos regionales (BID, CAF y Fonplata) hicieron que el proceso encontrara alternativas para mantenerse frente a la crisis del regionalismo sudamericano. La IIRSA, por lo tanto, sigue funcionando, ahora sin ese nombre y sin el aparato institucional multilateral regional.

Quizá si no hubiera esa posibilidad de seguir adelante con los proyectos sin Unasur, podríamos encontrar actores económicos que presionaran a los gobiernos para mantener la institucionalidad regional y garantizar que sus intereses siguieran siendo atendidos. También es posible suponer que los costos de abandonar Unasur serían mayores y podrían

78 Banco Interamericano de Desarrollo (BID), "BID, CAF y Fonplata lanzan Alianza por la integración regional”, BID, 3 de agosto de 2020, https:/ / www.iadb.org/pt/noticias/bid-caf-e-fonplata-lancam-alianca-pa ra-integracao-regional (consulta del 28 de octubre de 2020).

${ }^{79} \mathrm{El}$ proyecto presente en el sitio de ILAT (véase más en https://alian zailat.org/project/segunda-linea-de-500-kw-yacyreta-villa-hayes) ya componía la Cartera de Proyectos IIRSA/Cosiplan y su status aparecía como "en ejecución” en el sitio de IIRSA (véase más en http://www.iirsa.org/proyec tos/detalle_proyecto.aspx?h=317). 
reducir el estímulo de las posturas no integracionistas de los gobiernos.

\section{Consideraciones FinAleS}

$\mathrm{Al}$ analizar cómo las instituciones regionales sudamericanas reaccionaron a la crisis actual, a partir del caso de Unasur, este artículo se ha enfocado en el análisis del regionalismo sudamericano como un proceso dinámico que estructuró diferentes instituciones regionales, cada cual con su trayectoria, características y limitaciones. Al considerar los antecedentes críticos de cada proceso regional, se argumenta que las instituciones regionales en Sudamérica reaccionaron a la crisis de acuerdo con sus capacidades estructurales y, en ese sentido, algunas se presentaron más capaces que otras para reaccionar a las demandas que se presentaron en el periodo reciente.

En ese sentido, se refuerza lo entendido respecto a que la resiliencia de las instituciones dependen de sus antecedentes críticos, es decir, las características internas del proceso constituido. La inseguridad frente a la inestabilidad se configura como uno de los elementos críticos para el sostenimiento, avance o desmantelamiento de las instituciones creadas en la década de 2000. Al mismo tiempo se reconoce que esa tendencia afecta de forma distinta las experiencias de integración, aunque congreguen a los mismos actores, como consecuencia de las diferentes trayectorias institucionales de cada mecanismo regional.

El análisis sobre el caso de la Unasur nos permite vislumbrar que la actual crisis del regionalismo en América del Sur no es simplemente resultado de cambios políticos o de problemas personales entre presidentes, aunque estos elementos contribuyan a empeorar la crisis. Hay en la región problemas estructurales que dificultan la construcción de proyectos integracionistas más estables. A su vez, se concluye que el contexto histórico puede ser la oportu- 
nidad que estimule el proceso de la desintegración latinoamericana, pero no su causa.

La presencia de actores no gubernamentales es un factor que aumenta la capacidad de resiliencia de la integración, pero no impide modificaciones importantes o retrocesos. Los procesos de integración en América del Sur están subordinados a las lógicas políticas domésticas y a cada cambio electoral que se produce en un país miembro, de manera que encontramos repercusiones regionales, algunas favorables a la integración y otras críticas a ese proceso. La subordinación de los procesos a los cambios políticos internos intensifica la inestabilidad regional, ya subordinada a la inestabilidad económica y política de esas naciones.

Mientras esa lógica de subordinar los procesos regionales a las dinámicas nacionales permanezca, la tendencia es una sucesión de impulsos integracionistas seguidos de movimientos desintegradores y nuevos procesos de reconstrucción o relanzamiento de la integración, sin llegar realmente a estabilizar o profundizar de modo que sea posible garantizar una continuidad más estable. El problema reside en la dinámica que refuerza una lógica de regionalismo e integración que restringe las instituciones construidas en el largo plazo, con limitaciones estructurales para sostener las expectativas y los intereses de los Estados sudamericanos en relación con el ámbito del regionalismo en periodos de cambios o tensión en la región.

Al mismo tiempo, la lógica de establecer otros procesos integracionistas $\mathrm{u}$ otros mecanismos institucionales para atender los intereses nacionales estimula la inestabilidad de la integración, porque permite reducir los costos de abandonar el proyecto, como en el caso de IIRsa/Cosiplan. Y si bien a corto plazo eso puede resultar positivo, es verdad que aumenta las desconfianzas sobre los compromisos con la integración.

Una vez más se destaca que el contexto histórico es la oportunidad para el proceso de la desintegración regional, no su causa. Las limitaciones institucionales, resultantes de 
la trayectoria del regionalismo sudamericano, refuerzan una dinámica que depende directamente de cómo cada gestión gubernamental de estos países incorpora la integración regional y su entorno geográfico.

\section{BibLIOGRAFIA}

Arroyave Quintero, Mario, "La Unasur en la estrategia regional de Colombia y Brasil", en E. Pastrana Buelvas, S. Jost y D. Flemes (eds.), Colombia y Brasil: ¿socios estratégicos en la construcción de Suramérica?, Bogotá, Pontificia Universidad Javeriana/Fundación Konrad Adenauer, 2012, pp. 239-282.

Banco Interamericano de Desarrollo (BID), "BID, CAF y Fonplata lanzan Alianza por la integración regional”, BID, 3 de agosto de 2020, https://www.iadb.org/pt/noticias/bid-caf-e-fonpla ta-lancam-alianca-para-integracao-regional (consulta del 28 de octubre de 2020).

BarrenengoA, Amanda C., "De la unidad suramericana a la fragmentación regional: contradicciones en la Unasur a partir de las políticas de los gobiernos lulistas y las tensiones con las clases dominantes", Conjuntura Austral, 1, 56, 2020, pp. 77-93.

BarrenengoA, Amanda C., "¿Territorialidad neoliberal? Las políticas de desarrollo e integración física en tiempos del lulismo", Geograficando, 16, 1, 2020, pp. 1-14.

Briceño Ruiz, José y Andrés Rivarola (org.), Regionalism in Latin America: Agents, systems and resilience, Londres, Routledge, 2021.

Caldentey del Pozo, Pedro, "El regionalismo a examen. La crisis global de la integración", Revista de Fomento Social, 74, 3, 2020 , pp. 349-368.

Capoccia, Giovanni, "Critical Junctures", en K. O. Fioretos, T. G. Falleti y A. D. Sheingate (org.), The Oxford handbook of historical institutionalism, Reino Unido, Oxford University Press, 2016.

Capoccia, Giovanni y R. D. Kelemen, "The Study of Critical Junctures: Theory, Narrative, and Counterfactuals in Historical Institutionalism”, World Politics, 59, núm. 3, 2007, pp. 341-369, https://doi.org/10.1017/S0043887100020852 
Castilho, Martha, "Comércio Internacional e Integração Produtiva: uma análise dos fluxos comerciais dos países da Aladi”, Texto para Discussão IPEA 1705, enero de 2012, pp. 1-68.

Comisión Económica para América Latina (Cepal), Balance preliminar de las economias de América Latina y el Caribe, diciembre de 2000, LC/G.2123-P.

Comini, Nicolás M. y Alejandro Frenkel, "Unasur on the edge", en D. Nolte y B. Weiffen (org.), Regionalism under stress: Europe and Latin America in comparative perspective, Londres, Routledge, 2020.

Couto, Leandro F., "A Iniciativa para a Integração da Infra-estrutura Regional Sul-americana - IIRSA como instrumento da política exterior do Brasil para a América do Sul”, oIKos (Río de Janeiro), 5, 1, 2008, http://www.revistaoikos.org/seer/index.php/oik os/article/view/109

Fioretos, Karl, O., Tulia. G. Falleti y Adam Sheingate, "Historical Institutionalism in Political Science", en O. Fioretos, T. G. Falleti y A. Sheingate (org.), The Oxford Handbook of Historical Institutionalism (vol. 1), Reino Unido, Oxford University Press, 2016,https://doi.org/10.1093/oxfordhb/9780199662814.013.3

Fiori, José Luis, "A virada à esquerda na América do Sul”, Valor Econômico, 9 de enero de 2006, http://www.cnmcut.org.br/ conteudo/a-virada-a-esquerda-na-americado-sul (consulta de 13 de octubre de 2017).

Fuccille, Luis Alexandre, Marcelo P. Mariano, Harold Ramanzini Júnior y Rafael R. de A. Almeida, "O governo Dilma Rousseff e a América do Sul: A atuação brasileira na Unasul (2011-2014)", Colombia Internacional, 2017, pp. 43-72, https:// doi.org/10.7440/colombiaint92.2017.02

GonzÁlez, Guadalupe. G., Mónica Hirst, Carlos Luján, Carlos A. Romero y Juan Gabriel Tokatlian, "Coyuntura crítica, transición de poder y vaciamiento latinoamericano", Nueva Sociedad, 2021, núm. 291, https://nuso.org/articulo/coyuntura-cri tica-transicion-de-poder-y-vaciamiento-latinoamericano/

Hoffmann, A. R., "Mercosur between resilience and disintegration”, en D. Nolte y B. Weiffen (org.), Regionalism under stress: 
Europe and Latin America in comparative perspective, Londres, Routledge, 2020, pp. 119-132.

Hoffmann, Stephanie y Frédéric Mérand, "Regional Organizations à la Carte: the Effects of Institutional Elasticity", en T. V. Paul, International relations theory and regional transformation, Reino Unido, Cambridge University Press, 2012.

Honório, Karen dos Santos, "Política regional e projeção de interesses privados: Problematizando a América do Sul nos governos Lula", Carta Internacional, 14, 3, 2019, https://doi.org/10.215 30/ci.v14n3.2019.968

Honório, Karen dos Santos, "A política das obras e as obras da política: Um estudo sobre as relações bilaterais Brasil-Bolívia e Brasil-Equador na dimensão da infraestrutura nos governos Lula da Silva (2003-2010)", tesis de doctorado, Programa de Pós-Graduação em Relações Internacionais San Tiago Dantas, UNESP, Unicamp, PUC-SP, 2019, https://repositorio.unesp.br/ handle/11449/182283

Iniciativa para la Integración de la Infraestructura Regional Suramericana (IIRSA), Declaração de Brasília, Documentos IIRSA, diciembre de 2000, http://www.iirsa.org/admin_iirsa_web/ Uploads/Documents/comunicado_brasilia_esp.pdf

Iniciativa para la Integración de la Infraestructura Regional Suramericana (IIRSA), 10 años después: sus logros y desafíos, Comité de Coordinación Tecnica (CCT) y Secretaría del cCT, Buenos Aires, Documentos IIRSA, diciembre de 2011, http://www.iir sa.org/BancoMedios/Documentos20PDF/1b_iirsa_10_anios_ sus_ https:/ / www.iirsa.org/Document/Detail?Id=3356

Legler, Thomas, "Post-hegemonic regionalism and sovereignty in Latin America: optimists, skeptics, and an emerging research agenda", Contexto internacional, 35, 2013, pp. 325-352, https:/ / doi.org/10.1590/S0102-85292013000200001

Llenderrozas, Elsa, "Unasur: desafíos geopolíticos, económicos y de política exterior", Pensamiento Propio 42, s/v, 2016, pp. 195-214.

Mahoney, James, "Path Dependence in Historical Sociology", Theory and Society, 29 (4), 2000, pp. 507-548. 
Malamud, Andrés, "Presidential Diplomacy and the Institutional Underpinnings of Mercosur: an Empirical Examination", Latin American Research Review, 40, 1, 2005, pp. 138-164, https:// doi.org/10.1353/lar.2005.0004

Malamud, Andrés y Gian Luca Gardini, "Has Regionalism Peaked? The Latin American Quagmire and its Lessons", The International Spectator, 2012, 47, 1, pp. 116-133, https://doi.org/10.10 80/03932729.2012.655013

Mijares, Víctor Manuel y Sara Ramírez Hernández, "El factor Venezuela en la crisis del regionalismo posthegemónico”, documento de trabajo, 2020.

Mijares, Víctor. M. y Detlef Nolte, "Regionalismo posthegemónico en crisis. ¿Por qué la Unasur se desintegra?”, Foreign Affairs Latinoamérica 18, 3, 2018, pp. 105-112.

Mariano, Karina Lilia Pasquariello y Clarissa Correa Neto Ribeiro, "Regionalismo na América Latina no século xxi", en Rafael Salatini (org.), Cultura e direitos humanos nas relações internacionais, Marília, Cultura Acadêmica, 2016, p. 23-40.

Mariano, Karina Lilia Pasquariello, Bruno Theodoro Luciano y Regiane Nitsch Bressan, Integração com Democracia: o desafio para os parlamentos regionais, Río de Janeiro, Konrad Adenauer Stiftung, 2016, p. 228.

Neves, Bárbara Carvalho, "Política externa brasileira e a integração da infraestrutura na América do Sul: uma análise a partir dos mecanismos IIRSA/cosiplan", (tesis de maestría en Relaciones Internacionales - UNESP/UnICAMP/PUC-SP), Programa San Tiago Dantas de Pós-graduação em Relações Internacionais, São Paulo, 2019, p. 249, http://hdl.handle.net/11449/ 181007

Neves, Bárbara Carvalho, "Há uma luz no fim do túnel? Uma análise da situação atual do regionalismo sul-americano", Observatório de Regionalismo, 18 de febrero de 2020, http:/ / observatorio.repri.org/2020/02/18/ha-uma-luz-no-fim-do-tunel-u ma-analise-da-situacao-atual-do-regionalismo-sul-americano/

Nolte, Detlef, “The Pacific Alliance Regionalism without stress?”, en D. Nolte y B. Weiffen (org.), Regionalism under stress: Europe 
and Latin America in comparative perspective, Londres, Routledge, 2020, pp. 150-167.

Nolte, Detlef y Brigitte WeIfFen, "Introduction - Regionalism under stress", en D. Nolte y B. Weiffen (org.), Regionalism under stress: Europe and Latin America in comparative perspective, Londres, Routledge, 2020, pp. 15-33.

Nolte, Detlef y Nicolás Matías Comini, "Unasur: Regional Pluralism as a Strategic Outcome”, Contexto Internacional 38, 2, 2016.

Ocampo, José Antonio, "Retomar la agenda del desarrollo", Revista de la Cepal 74, 2001, pp. 7-20.

Pierson, Paul, Politics in time: History, institutions, and social analysis, New Jersey, Princeton University Press, 2004).

Pierson, Paul y Theda Skocpol, "El institucionalismo histórico en la ciencia política contemporánea”, Revista Uruguaya de Ciencia Política, 17, 1, 2008, pp. 7-38.

Quiliconi, Cintia y Raúl S. Espinoza, "Latin American Integration: Regionalism à la Carte in a Multipolar World?", Colombia Internacional 92, 2017, pp. 1-41, https://doi.org/10.7440/co lombiaint92.2017.01

Riggirozzi, Pía, "Coronavirus y el desafío para la gobernanza regional en América Latina”, Análisis Carolina-Fundación Carolina, 12, 2020.

Ruvalcaba, D. M., "Institucionalidad de la Unión de Naciones Suramericanas (Unasur): Balance de su primera década de existencia, 2008-2017", en J. A. P. Coronado et al., Dimensiones, estrategias y alternativas de la integración autónoma para América Latina y el Caribe. Desafios para el caso mexicano (2010-2015), Tomo II, Guadalajara, Conacyt, Red de Investigación sobre la Integración de América Latina y el Caribe (Redialc), 2018, pp. 177-198.

SanahuJa, José Antonio, "Del 'regionalismo abierto' al 'regionalismo post-liberal'. Crisis y cambio en la integración regional en América Latina", Anuario de la Integración Regional de América Latina y el Gran Caribe 2008-2009, 2009, pp. 11-54.

Sanahuja, José Antonio y López Burian, Camilo, "Latin American neo-patriot far-right: Between the crisis of globalisation and regional political processes", en Gisela Pereyra Doval y 
Gastón Souroujon (eds.), Global Resurgence of the Right, Londres, Routledge, 2021.

Serbin, Andrés, "América del Sur en un mundo multipolar: ¿es la Unasur la alternativa?”, Nueva Sociedad, 2009, p. 219.

Slater, Dan y Erica Simmons, "Informative Regress: Critical Antecedents in Comparative Politics", Comparative Political Studies, 43, 7, 2010, pp. 886-917, https://doi.org/10.1177/0010414010 36134

SouzA, Lucas Eduardo Silveira de, "O Brasil e o regionalismo sulamericano: o papel da UNASUL na política externa do governo Rousseff (2011-2016)", tesis de maestría en Relaciones Internacionales, Universidade de Brasília, 2018, 155 pp., https://re positorio.unb.br/handle/10482/34899

Teixeira Júnior, Augusto W. M. y Antonio H. Lucena Silva, "Explaining Defense Cooperation With Process-tracing: The Brazilian Proposal for the Creation of Unasur South American Defense Council", Revista Brasileira de Política Internacional 60, 2, 2017, pp. 1-18.

Tratado Constitutivo da União de Nações Sul-Americanas-Brasilia, 23 de mayo de 2008, Unasur, 2008, http:/ /www.itamaraty.gov. br/images/ed_integracao/docs_UNASUL/TRAT_CONST_ PORT.pdf (consulta del 20 de octubre de 2020).

VAdell, Javier. A. y Clarisa Giaccaglia, "El rol de Brasil en el regionalismo latinoamericano: La apuesta por una inserción internacional solitaria y unilateral”, Foro internacional, 60, 3, 2020, pp. 1041-1080.

Veiga, Pedro da Motta y Sandra P. Ríos, "O Regionalismo PósLiberal na América do Sul: origens, iniciativas e dilemas”, Cepal, Serie Comercio Internacional, 82, 2007.

WeIFFEN, Brigitte, "Stress factors and their impact on regionalism", en D. Nolte y B. Weiffen (orgs.), Regionalism under stress: Europe and Latin America in comparative perspective, Londres, Routledge, 2020, pp. 15-33. 
